\title{
Effects of Voluntary Summer Learning Programs on Low-Income Urban Youth
}

This first-ever assessment of the effectiveness of large-scale, voluntary, district-run summer learning programs serving

low-income elementary students began with 5,637 children.

With a limited number of slots, 3,192 were invited

to participate in consecutive summer learning programs-one before 4th grade (2013) and one before 5th grade.

The remaining 2,445 children served as a control group.
3,192

rising 4th graders

were given the

opportunity to attend

two summers of

programming

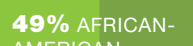

$49 \%$ AFRICAN-
AMERICAN

$38 \%$

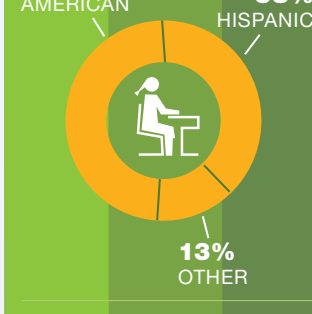

The study was

conducted in five

school districts

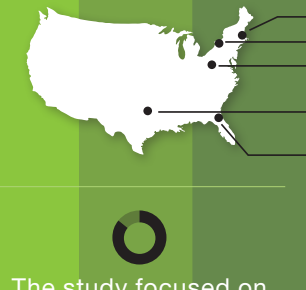

The study focused on low-income students:

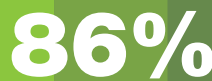

qualified for free

qualified for free or
reduced price lunch

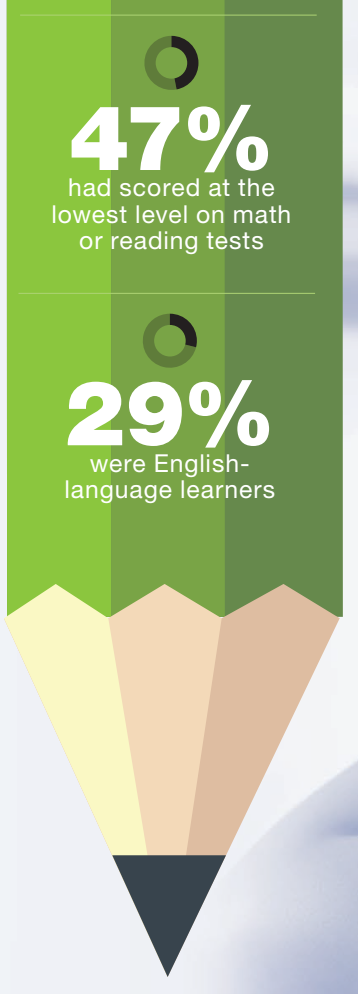

Kids with high attendance performed better in math and reading after two

Summers compared with students in the control group, who were not invited to participate in the programs.

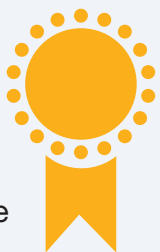

These findings are correlational but very likely due to the summer learning programs. The differences in the performance between the "high attenders" and the control group are the equivalent of about $20 \%-25 \%$ of a year's learning in language arts and math at this age. These benefits persisted throughout the 5 th-grade school year.
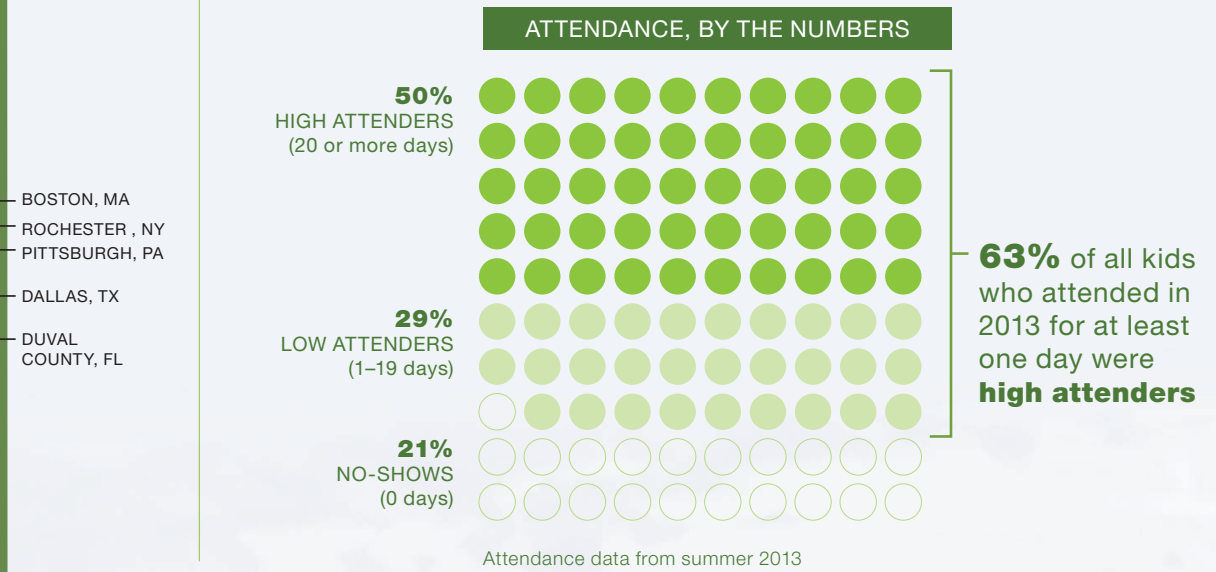

www.rand.org

This work was commissioned by The Wallace Foundation

Excerpted from Learning from Summer: Effects of Two Years of Voluntary Summer Learning Programs on Low-Income Urban Youth, Catherine H. Augustine et al., RAND Corporation, RR-1557, 2016. The RAND Corporation is a research organization that develops solutions to public policy challenges to help make communities throughout the world safer and more secure, healthier and more prosperous. RAND is nonprofit, nonpartisan, and committed to the public interest. 


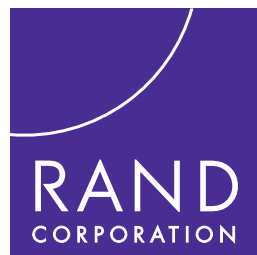

CHILDREN AND FAMILIES

EDUCATION AND THE ARTS

ENERGY AND ENVIRONMENT

HEALTH AND HEALTH CARE

INFRASTRUCTURE AND

TRANSPORTATION

INTERNATIONAL AFFAIRS

LAW AND BUSINESS

NATIONAL SECURITY

POPULATION AND AGING

PUBLIC SAFETY

SCIENCE AND TECHNOLOGY

TERRORISM AND HOMELAND SECURITY
The RAND Corporation is a nonprofit institution that helps improve policy and decisionmaking through research and analysis.

This electronic document was made available from www.rand.org as a public service of the RAND Corporation.

\section{Support RAND}

Browse Reports \& Bookstore

Make a charitable contribution

\section{For More Information}

Visit RAND at www.rand.org

Explore the RAND Corporation

View document details

\section{Infographic}

RAND infographics are design-focused, visual representations of data and information based on a published, peer-reviewed product or a body of published work.

\section{Limited Electronic Distribution Rights}

This document and trademark $(s)$ contained herein are protected by law as indicated in a notice appearing later in this work. This electronic representation of RAND intellectual property is provided for noncommercial use only. Unauthorized posting of RAND electronic documents to a non-RAND website is prohibited. RAND electronic documents are protected under copyright law. Permission is required from RAND to reproduce, or reuse in another form, any of our research documents for commercial use. For information on reprint and linking permissions, please see RAND Permissions. 